\title{
Diversity and Structure of Intergenerational Relationships: Elderly Parent-Adult Child Relations in Korea
}

\author{
Keong-Suk Park • Voonchin Phua • James McNally • \\ Rongjun Sun
}

Published online: 30 September 2006

(C) Springer Science + Business Media, Inc. 2006

\begin{abstract}
Korean society has undergone a rapid demographic transition that has challenged traditional patterns of family exchanges. The structure and directions of support flows have become more complex as multiple generations coexist. This article examines the complexity of contemporary Korean intergenerational relationships. The study analyzed two different samples to address anticipated differences in perceptions of and attitudes toward relationships between adult children and elderly parents. The researchers used maximum likelihood latent structure analysis to discover the latent patterns of the association among three main subdimensions of intergenerational relationships: geographic proximity, exchange of support, and cultural norms of family support. Results show that the perspectives on intergenerational relationships differ significantly between middle-aged children and elderly parents. Intergenerational relationships among middle-aged adults comprise five distinct patterns: strong reciprocal, strong traditional, intermediate normative, intermediate circumstantial, and weak. The interpretation of intergenerational relationships from the elders' perspectives is more straightforward, with only three patterns: traditional, reciprocal, and weak. Along with significant socioeconomic differences in the prevalent patterns of intergenerational relationships, these results emphasize the complex interplay of contingency and path dependency in diversifying the value and support exchanges of intergenerational relationships.
\end{abstract}

\section{K.-S. Park ( $\square)$}

Department of Sociology, Dong-A University, Busan 602-103, Korea

e-mail: pks0505@dau.ac.kr

\section{Phua}

Department of Sociology and Anthropology, Gettysburg College, 300 North Washington Street, Campus Box 412, Gettysburg, PA 17325, USA

e-mail: vphua@gettysburg.edu

J. McNally

National Archive of Computerized Data on Aging, Inter-University Consortium for Political and Social Research, Ann Arbor, MI, USA

R. Sun

Department of Sociology, Cleveland State University, Cleveland, OH, USA 
Keywords Exchange of support - Generational relationship - Geographic proximity · Korea $\cdot$ Norms of family support

\section{Introduction}

In recent decades, Korean society has undergone a rapid demographic transition that has challenged traditional patterns of family exchange. The terms soja-wha ("low fertility") and korung-wha ("aging") reflect Koreans' growing recognition of the effects that the declining number of young people, the increasing number of elders, and the coexistence of multiple generations are having on family structures. The structure and directions of support flows have become more complex as multiple generations coexist. Further confounding this complexity are evolving differences in intergenerational values, interests, and ways of life between generations that may not correspond with traditional social responses.

Family change is at the center of debate in academic and policy making fields in Korea. The prevalence of intergenerational coresidence has greatly declined over time (Kwon \& Park, 1995). The proportion of elders in non-family households has increased tremendously. The types and the extent of generational exchange of emotional and instrumental support vary according to socioeconomic status and generation. Attitudes toward hyo ("filial piety") differ between young and old generations as younger persons are less likely than older persons to emphasize children's responsibility for taking care of elderly parents.

In order to explain these complex changes in intergenerational relationships, some researchers argue that both traditional traits and new values coexist, as in a transitory stage of social development. Others argue that the durability of Korean cultural uniqueness will survive despite rapid social changes (Choi, 2002). Still others argue that the tradition and cultural value of family centrality has been reinvented in the modernization process (Chang, 1997).

What these controversial stances fail to address is the fluid and complex nature of intergenerational relationships. Like all other social phenomena, intergenerational behaviors are constantly being reconstructed in response to the strategic needs and values of family members in the face of social change and the opportunities for economic development. Previous studies on intergenerational relationships tend to focus narrowly on only one aspect of family change (such as intergenerational coresidence), which ignores the complex construct of intergenerational relationships fabricated by differential norms, interest, and power relationships.

The concept of intergenerational relationships is abstract and complex and is best represented by multiple dimensions, such as norm, function, power, and structure (Hogan, Eggebeen, \& Clogg, 1993; Silverstein \& Bengtson, 1997). This article aims to examine the complexity of contemporary intergenerational relationships in Korean society. This article focuses on the three main subdimensions of intergenerational relationships: geographic proximity, exchange of support, and cultural norms of family support.

Three Dimensions of Intergenerational Relationships: Geographic Proximity, Exchange of Support, and Norms of Family Support

Intergenerational relationships do not operate along a single dimension. Instead, they represent a complex set of simultaneous interactions along a series of dimensions including geographic proximity, frequency and type of contact, level and form of exchange, emotional or normative affinity, and cultural expectations. For the purpose of this article, 
we chose to summarize these dimensions formally into three specific theoretical clusters of activities: geographic proximity, exchange of support, and cultural norms of family support. We argue that these three clusters represent key composites of intergenerational relationships from structural, functional, and normative perspectives.

\section{Generational Proximity: Indicator of Solidarity or Poverty?}

Geographic proximity facilitates the regular intergenerational contact that is important for exchanging social and economic support as well as for maintaining familial solidarity. Specifically, it has been argued that coresidence helps promote daily contact and interaction and contributes to the maintenance of material and emotional exchanges between generations. However, high levels of geographic mobility in both Western and nonWestern societies have significantly reduced opportunities for many adults to engage in both intergenerational coresidence and routine contact. Yet technological advances have helped reduce the cost of both communication and travel, making contact among noncoresident family members less expensive and easier to achieve. These advances have helped to minimize obstacles to maintaining and reinforcing the positive elements of intergenerational relationships once presented by distance. In response to this technological shift, a number of studies on American families in the 20th century have questioned the validity of treating coresidence as the primary indicator of strong intergenerational ties and support networks (Litwak, 1985; Shanas, 1980). According to this perspective, coresidence is more likely to occur among groups with lower chances of social mobility and independent living and, as a result, coresidence should be regarded as an indicator of poverty rather than of intergenerational ties (Litwak, 1985).

The contrasts between cultural and economic accounts of coresidence are also quite distinct when evaluating primary determinants leading to coresidence (Phua, Kaufman, \& Park, 2001). Cultural approaches typically emphasize the importance of long-standing cultural norms and the durability of extended family and family centeredness. In contrast, economic approaches focus on the costs, benefits, and opportunities of coresidence and the response of family structures to shifts in the socioeconomic structure of society due to development, modernization, or innovation (Burr \& Mutchler, 1991; DaVanzo \& Goldscheider, 1989; Wolf \& Soldo, 1988).

In Korea, the prevalence of intergenerational coresidence has declined greatly over time. As of 1966, the proportion of households in which elders aged 65 and older lived alone or with a spouse was only $7.0 \%$. By 1980 , this proportion had more than doubled to $14.7 \%$. The percentage of elders living alone or with a spouse increased from $26.7 \%$ in 1990 to 45.4\% in 2000 (Korean National Statistical Office, 1966; 1980; 1985; 1990; 1995; 2000).

As coresidence has become less common, its importance as a desirable social norm has also changed. Traditional culturally grounded perspectives have argued that coresidence of elderly parents with their children is a natural phenomenon that is taken for granted. On the other hand, economic perspectives argue that coresidence with adult children is more likely to occur when there is a need or a demand for support, such as in cases of poverty and poor health. In reality, intergenerational support mechanisms that are played out through coresidence are constructed in a much more complicated manner that draws from both approaches. Two examples from Korea illustrate how coresidence reconstructs its meaning and changes itself as a main part of the contemporary family relation. First, newly established families and newlyweds will often live in their parents' home because of both tradition and economic considerations. This type of coresidence was once a long-term relationship with the expectation that the son would assume control of the parents' home and property, while the wife would care for the elderly parents. 
Now, these residential choices are often temporary and reflect a short-term adjustment. Similarly, working mothers sometimes choose to live with elderly parents in order to use the informal labor of the parents as a mechanism to reduce the burden of housework and childrearing. The use of parents as informal labor represents a marked contradiction in traditional roles of Korean women and reflects the ongoing adjustment of intergenerational exchanges in the face of new economic realities and opportunities for women.

\section{Exchange of Support: Who Benefits Whom?}

The majority of Korean middle-aged adult children provide financial support to their elderly parents. The importance of financial support for old age security is closely related to the low socioeconomic status of elderly adults. Like elders in many newly developed nations, most of the current generation of aged Koreans do not have pension benefits or significant accumulations of individual assets outside of home ownership.

According to exchange theories that draw from economic perspectives, the stability and durability of relationships depend upon reciprocity of the perceived benefits of these exchanges to both parties (Dowd, 1975). In this regard, the most stable relationships occur when the perceived benefits of exchange are equal between partners. When a lack of reciprocity exists, these relationships have a higher risk of dissolution and can lead to alienation and segregation between parties formerly aligned with one another. From this perspective, exchange theorists try to link levels of alienation experienced later in life to the social environments that deprive elders of essential social resources associated with traditional intergenerational relationships.

Evaluating the benefits of intergenerational exchange relationships requires that researchers operationalize the measurement of subjective processes. Exchange behaviors between family members are prevalent in all societies and typically consist of both material and non-material rewards, including money, goods, services, and psychological supports such as prestige, honesty, and legitimacy. Still, the perceived benefits and value of family exchanges often vary from person to person and can have different values at different junctures in the life course. At issue is how to estimate the manner in which reciprocity is evaluated within intergenerational relationships. This estimation process needs to recognize the long-term perspective of these support exchanges. This is because intergenerational relationships are established over the entire life course of both the individual and the family. The provision of support obtained by elders in later life, for example, could be seen as reimbursement for care provided to adult children when they were dependent earlier in life.

\section{Normative Bases of Intergenerational Relationships: The Changing Meaning of Filial Piety}

In Korea, the norm of filial piety known as hyo exists. Traditionally, hyo means that when children behave in a socially acceptable manner they will provide not only financial and physical care for elderly parents, but also respect. The central goal is for children to behave in a manner that makes their elderly parents happy. Although hyo remains a recognized value today, the social interpretation of what constitutes appropriate behavior toward elderly adults has changed significantly over time. Younger generations of adults are more likely than are elders themselves to emphasize elderly adults' personal responsibility for their own care (Korean National Statistical Office, 1999).

Previous studies also suggest that the meaning of hyo has changed among elderly adults themselves. Elders today are less likely than those in the past to perceive that they will automatically receive care from children (Park, 1999). Similarly, there has been a change in the way elders define support. Unlike those of previous generations, the elders of today 
emphasize emotional rather than material forms of support from their children as the virtue of hyo. Happiness among elderly parents has now been translated into their enjoyment of the successes and social achievements of their children. This change in perception of hyo suggests that elders may increasingly view the provision of one-sided help from their children as a burden for their children rather than as a duty. Many elderly parents continue to rely upon their children because of their lack of self-reliance and legitimize it by the norm of hyo. Nevertheless, the discomfort and inner conflict associated with accepting this level of help appears to be growing among elderly adults.

Contemporary intergenerational relationships are both complex and diverse. The prevalence of coresidence has declined for all groups in Korea and the number of elders living alone has increased greatly since the 1980s. At the same time, the mechanisms by which traditional social norms regarding the support of elderly adults are maintained have become more diverse. It is also important to recognize that the pace of change varies within the subdimensions of intergenerational relationships. This differential pace of change has often resulted in contradictions in exactly what perceived responsibilities toward elders should be and who is responsible for meeting these needs. These contradictions are the result of the rapid pace of social change within Korean society since the 1960s that has resulted in increased intergenerational heterogeneity from both a cultural and an economic perspective.

The associated factors leading to the maintenance of intergenerational support (geographic proximity, exchange of support, and norms of family support) represent conjoined functions that interact with one another in complex ways. Consequently, studying only one aspect of these dimensions could result in misleading outcomes and a biased understanding about potential causes and transitions of intergenerational support mechanisms. The present study employs a relatively underutilized statistical approach to identify the structural patterns that define intergenerational relationships and the causal factors that underlie the complex and contradictory factors reflecting intergenerational relationships in Korea.

\section{Materials and Methods}

\section{Research Methods}

Intergenerational relationships are an abstract concept that cannot be directly observed. Furthermore, the measurement of geographic proximity, exchange of support, and norms of family support is likely to represent incomplete indicators of intergenerational relationships when treated individually. To address this concern, the present study employs maximum likelihood latent structure analysis to examine the underlying patterns of intergenerational relationships based on the knowledge of the association among the three subdimensions shown in figure 1. The Categorical Data Analysis System provides a useful tool to extract multidimensional factors based on observed associations among categorical variables (Eliason, 1997).

If a latent structure underlying intergenerational relationships represents the true source of the association among observed measures of this relationship, the observed association is likely to reduce random noise within each level of the latent pattern. This condition, defined as local independence, assumes the joint probability $\left(\mathrm{p}_{i j k}{ }^{*}\right)$ among the observed measures, and can be estimated as

$$
\mathrm{p}_{i j k}{ }^{*}=\sum_{w} \pi_{i w}^{A / X} \times \pi_{j w}^{B / X} \times \pi_{k w}^{C / X} \times \pi_{w}^{X},
$$


Observed Variables

Latent Factors

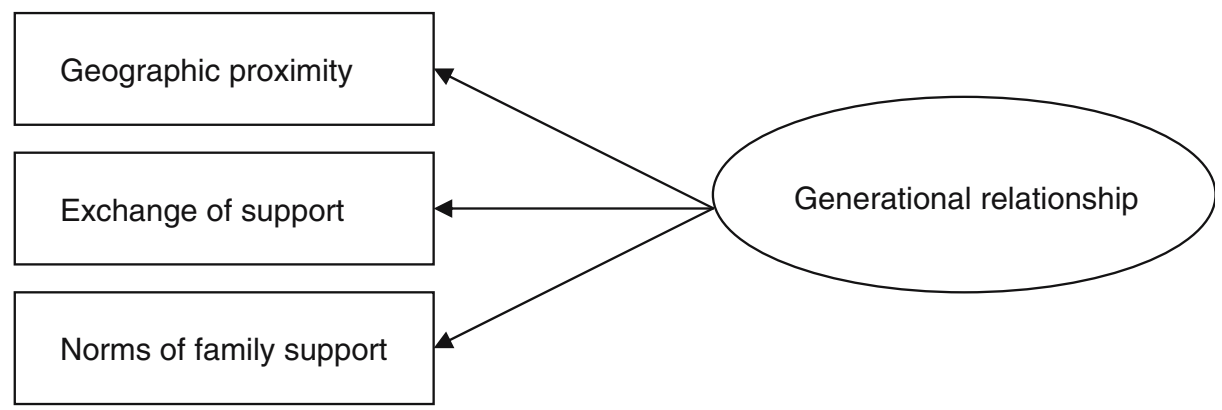

Figure 1 Observed variables and latent factors of generational relationships.

where $\pi_{w}^{X}$ is the probability of pattern $w$ of the latent structure $X$. The three probabilities on the right side of the equation $\left(\pi_{\mathrm{iw}}^{A / X}, \pi_{j w}^{B / X}, \pi_{k w}^{C / X}\right)$ refer to the conditional probabilities of the specific levels $i, j$, and $k$ of variables $A, B$, and $C$ at the given pattern $w$ of the latent structure. The probabilities of the latent patterns and the conditional probabilities given the level of latent pattern are estimated using an Estimation Maximization algorithm. To find the best-fit model, the model fitting process is replicated, differentiating the number of latent patterns. Comparison of the model fit under various assumptions regarding the latent patterns used likelihood ratio statistics, $\mathrm{L}^{2}$.

Data

The perceived meaning and value of an intergenerational relationship are likely to differ depending upon whether it is viewed from the perspective of the adult children or their parents. In this study, we used two different samples to address anticipated differences in perceptions of and attitudes toward intergenerational relationships between adult children and elderly parents.

First, we drew data on adult children from a nationally representative sample of adults aged 40-59 collected by Kim, Park, and Lee (1999). The total sample size was 1,200 adults. Kim and colleagues' survey was conducted to examine changing attitudes regarding intergenerational relationships and shifts in retirement planning among middle-aged adults in Korea. From the total sample of 1,200, we selected 864 adults with living parents in order to examine their relationship with their elderly parents. One limitation of Kim and colleagues' survey is that it was designed to examine patrilineal intergenerational relationships, as these relationships have been traditionally emphasized until quite recently in Korea. This limitation derived from the survey design did not allow us to fully consider intergenerational relationships from both gender perspectives, such as relationships between male respondents and their parents-in-law or between female respondents and their own parents. Because we took into account gender differences in the patrilineal relationships themselves, we conducted separate analyses according to respondents' gender.

We obtained data on elderly parents from a nationally representative survey on elderly adults conducted in 1998 by the Korean Institute of Health and Social Affairs (Jung, Joe, Oh, Byun, \& Moon, 1998). Using information on children living either with or apart from elderly respondents, we constructed a data set of paired elderly parents and their children. The total sample size of the elderly parent-adult child data set was 2,496 cases. 


\section{Measurement of Variables}

Measures of intergenerational relationships We measured geographic proximity between the elderly parents and their children using a dummy variable where $1=$ coresidence with an adult child and $0=$ all other residential forms. In Korea, the residential pattern of elderly parents and their children living separately but in close distance is not the prevailing one, and the data set for the adult children used in this study did not provide detailed information about geographic distance among elderly parents living apart from their children. For this reason, geographic proximity was measured simply as coresidence or non-coresidence.

The variables operationalizing exchanges of support measured the way in which elderly parents and their children exchanged economic, instrumental, and emotional support. Economic support included financial help, such as money to help with living expenses or fees associated with the costs of maintaining a household. Instrumental support covered health care, cleaning, housework, and the raising of grandchildren. Emotional support referred to counseling, advising, and listening to one another. The observed distribution of support flows suggested that economic help was strongest from adult children to elderly parents; minimal support moved from the parents to the adult children. The percentage of adult children reporting that they provided financial help to their elderly parents and the percentage of elderly parents reporting that they received economic support from adult children were both about $66 \%$ (see Table 1). In contrast, the percentage of adult children reporting that they received economic help from elderly parents and of elderly parents reporting that they gave help to adult children each represented only about $20 \%$ of the sample.

Instrumental support also reflected asymmetrical support flows between the two generations. Table 1 shows that $41.6 \%$ of adult children reported that they provided

Table 1 Measurement of generational relationships.

\begin{tabular}{|c|c|c|c|}
\hline Variable & Outcome & $\begin{array}{l}\text { Middle-aged } \\
\text { children } \\
\text { reporting } \\
(\%, N=864)\end{array}$ & $\begin{array}{l}\text { Elderly parents } \\
\text { reporting } \\
(\%, N=2,496)\end{array}$ \\
\hline $\begin{array}{l}\text { Geographic proximity (whether elderly } \\
\text { parents and their children live together) }\end{array}$ & Coresidence & 20.3 & 46.6 \\
\hline \multirow{2}{*}{$\begin{array}{l}\text { Economic support (financial support } \\
\text { such as housing, food, clothing, medical } \\
\text { costs, etc.) }\end{array}$} & Gave economic support & 65.4 & 20.6 \\
\hline & Received economic support & 23.2 & 66.1 \\
\hline \multirow{2}{*}{$\begin{array}{l}\text { Emotional support (counseling, listening } \\
\text { to problems, giving advice, etc.) }\end{array}$} & Gave emotional support & 60.0 & 24.4 \\
\hline & Received emotional support & 42.0 & 48.7 \\
\hline $\begin{array}{l}\text { Instrumental support I (whether or not } \\
\text { children are primary caregiver for elders } \\
\text { in need of long-term care services) }\end{array}$ & Received care from children & - & 48.3 \\
\hline \multirow{2}{*}{$\begin{array}{l}\text { Instrumental support II (housework, } \\
\text { care, help, etc.) }\end{array}$} & Gave instrumental support & 41.6 & - \\
\hline & $\begin{array}{l}\text { Received instrumental } \\
\text { support }\end{array}$ & 19.2 & - \\
\hline $\begin{array}{l}\text { Norm of family support I (attitude } \\
\text { toward old age security) }\end{array}$ & $\begin{array}{l}\text { Family is most responsible } \\
\text { for old age security }\end{array}$ & - & 35.6 \\
\hline $\begin{array}{l}\text { Norm of family support II (attitude } \\
\text { toward children's support for } \\
\text { elderly parents) }\end{array}$ & $\begin{array}{l}\text { It is a duty or norm for } \\
\text { children to provide care } \\
\text { for elderly parents }\end{array}$ & 39.2 & - \\
\hline
\end{tabular}


instrumental help to elderly parents, whereas only $19.2 \%$ of adult children reported receiving instrumental support from their parents. As would be expected, the proportion of adult children receiving emotional support from elderly parents was relatively higher than that receiving economic and instrumental support. Whereas $60 \%$ of adult children reported providing emotional support to elderly parents, only $42 \%$ reported receiving some level of emotional support from their elderly parents.

Norms of family support were measured by two questions drawn from the surveys. Middle-aged adults were asked the question "What do you think about children taking care of their elderly parents?" In response to this question, 39.2\% of adult children responded that this activity was to be "taken for granted or treated as a duty." Similarly, the survey instrument for the elderly sample asked, "Who do you think is most responsible for old age security?" In response to this question, only $35.6 \%$ of the elderly parents emphasized that this responsibility was primarily that of the family or the children. Both sets of responses suggest that although traditional norms of filial responsibility remain powerful in Korea, they no longer represent the predominant view among either adult children or their aged parents.

Independent variables and control variables The independent or control variables chosen for the model attempted to capture the extent of obligation for providing intergenerational family support based upon geographic availability, level of resources, and the perceived need for intergenerational support behavior. Table 2 summarizes the measurement of these characteristics among adult children. Because of the traditional structure of Korean intergenerational support networks, sibling relationships were measured only along patrilineage. Consequently, references to sibling relations for a male respondent relate to siblings of the male respondent whereas references to sibling relations for a female respondent relate to the siblings of the woman's husband. The sibling rank variable measured whether the male respondent or the husband of a female respondent was the eldest male in the family. The sibling number variable represents the total number of brothers and sisters of the male respondent or of the woman's husband (including the respondent).

We categorized educational level into a series of dummy variables: primary school, middle school, and high school. Having some college or more was the reference category. We measured occupation through five independent and exclusive categories: clerical, sales/ service, agricultural, production/none, with the reference category being professional/ official occupation. Because spousal occupation was asked of female respondents only, information on the wife's occupation is not available for male respondents. The figure in Table 2 represents female respondents' own economic status so that the sample size is reduced to 390 .

Family income was measured as the sum of wages, monetary and real estate interest, and pension benefits. Subjective sense of economic status was also taken into account with four categories: upper middle, middle, lower middle, and low. Considering regional differences in generational relationship, we measured place of residence as Dong (administrative unit of city) or elsewhere.

The characteristics of the elderly parents and their self-reliance in economic and physical terms as captured in our models are presented in Table 3 . We measured economic resources among elderly parents as their total amount of wealth from work, monetary and real estate interest, children's support, pensions, and other transfers. As shown in Table 3, more than two thirds of elderly parents had income levels less than 500,000 won, reflecting the near poverty of most elderly Koreans. We treated employment as a dummy variable where $1=$ working and $0=$ not working. More than one third of elderly respondents reported working. 
Table 2 Characteristics of adults aged 40-59, $1999(N=864)$.

\begin{tabular}{lll}
\hline Characteristic & Outcome & \\
\hline Gender, percent of male & $54.9(864)$ & \\
Age, \% & Husbands & Wives \\
$40-44$ & 35.5 & 43.0 \\
$45-49$ & 21.6 & 21.4 \\
$50-54$ & 28.2 & 28.6 \\
$55-59$ & 14.7 & 6.9 \\
Total & $100.0(815)$ & $100.0(737)$ \\
Education, \% & Husbands & Wives \\
Primary school & 4.6 & 9.9 \\
Middle school & 10.1 & 20.3 \\
High school & 53.6 & 56.8 \\
College or more & 31.7 & 12.9 \\
Total & $100.0(840)$ & $100.0(857)$ \\
Occupation, \% & Husbands & Wives \\
Professional & 10.1 & 1.8 \\
Clerical & 24.2 & 1.0 \\
Sales/service & 38.8 & 29.2 \\
Production & 17.1 & 11.5 \\
Agricultural & 4.2 & 1.5 \\
None & 5.6 & 54.9 \\
Total & $100.0(840)$ & $100.0(390)$ \\
Husband's sibling rank, percent of eldest & $36.5(864)$ & \\
Husband's sibling number, Mean & 5.2 sibling $(864)$ & \\
Monthly family income, Mean(10,000 won) & $202(864)$ & \\
Subjective economic status, \% & & \\
Upper middle & 8.8 & \\
Middle & 51.4 & \\
Lower middle & 31.8 & \\
Low & 8.0 & \\
Total & $100.0(864)$ & \\
Home owner, \% & $82.1(864)$ & \\
Resident of Dong, \% & $79.3(864)$ & \\
\hline & & \\
& & \\
& &
\end{tabular}

Figures in parentheses are frequencies. Change in frequencies is mostly due to unavailable data, such as spousal variables for unmarried respondents. The case limitation of wife's occupation is due to survey design that did not include information on spousal occupations for male respondents.

In contrast to that of adult children, the educational level of the elderly parents is very poor: about four fifths of the elders had an educational level of primary school or less. To measure the impact of education in our model, we created a dummy variable where $1=$ primary school education and $0=$ middle school education.

We were also interested in measuring the effect of social activities on the quality of the intergenerational relationship. In our model, the elderly respondent's involvement in activities such as religious organizations, clubs, cultural organizations, social movements, and volunteer groups was summed and treated as a measure of total social activity.

The activities of daily living score was employed to measure the health status of the elderly respondents. This score is the sum of the limitations the elderly adults experienced with bathing, clothing, eating, getting into or out of a chair, walking, and toileting. About $66 \%$ of elderly respondents reported having no problems with these six items. 
Table 3 Characteristics of elders aged 65 and older, $1998(N=2,496)$.

\begin{tabular}{|c|c|}
\hline Characteristic & Outcome \\
\hline Male, $\%$ & $38.6(2,496)$ \\
\hline \multicolumn{2}{|l|}{ Age, $\%$} \\
\hline $65-69$ & 38.4 \\
\hline $70-74$ & 29.1 \\
\hline $75-79$ & 17.9 \\
\hline $80+$ & 14.5 \\
\hline Total & $100.0(2,496)$ \\
\hline Married, \% & $52.0(2,496)$ \\
\hline Educated beyond primary school, \% & $14.5(2,495)$ \\
\hline \multicolumn{2}{|l|}{ Individual income, $\%$} \\
\hline Less than 100,000 won & 18.9 \\
\hline $100,000-500,000$ won & 55.5 \\
\hline $500,000-1,000,000$ won & 17.5 \\
\hline $1,000,000$ won and more & 8.1 \\
\hline Total & $100.0(2,496)$ \\
\hline Employed, \% & $36.4(2,495)$ \\
\hline Problems with activities of daily living, $\%$ & $34.5(2,493)$ \\
\hline Resident of the city, $\%$ & $61.3(2,496)$ \\
\hline Mean number of children & 4.84 children \\
\hline $\begin{array}{l}\text { Mean number of social activities such as religious activities, } \\
\text { club meetings, cultural activities, social movements, volunteer groups }\end{array}$ & 0.80 activities \\
\hline Home owner, \% & $79.4(2,493)$ \\
\hline \multicolumn{2}{|l|}{ Family income, $\%$} \\
\hline Less than 400,000 won & 32.0 \\
\hline $400,000-800,000$ won & 27.3 \\
\hline $800,000-1,500,000$ won & 23.2 \\
\hline $1,500,000-2,000,000$ won & 8.1 \\
\hline $2,000,000-3,000,000$ won & 6.4 \\
\hline $3,000,000$ won and more & 3.1 \\
\hline Total & $100.0(2,469)$ \\
\hline
\end{tabular}

Figures in parentheses are frequencies.

The place of residence of the elderly respondent and the reported number of children were used as indicators of the opportunities or constraints for engaging in intergenerational relationships with adult children. On average, $61.3 \%$ of elderly respondents lived in an urban area, with a mean number of 4.84 children across the sample. In addition to these variables we controlled for gender, age, and marital status as these variables are related to economic and physical independence.

\section{Results}

Association Among Geographic Proximity, Exchange of Support, and Norms of Family Support

Initially we examined the pattern of association among the three observed dimensions of intergenerational relationships. Summary results of two-way cross-tabulation among the 
Table 4 Association among the dimensions of generational relationships for middle-aged adults, 1999.

\begin{tabular}{|c|c|c|c|c|}
\hline \multirow[t]{2}{*}{ Dimension } & \multicolumn{2}{|c|}{ Geographic proximity } & \multicolumn{2}{|c|}{ Norm of family support } \\
\hline & Living together & Living separately & Normative & Circumstantial \\
\hline \multicolumn{5}{|c|}{ Instrumental/economic support } \\
\hline Reciprocal & 55.4 & 17.0 & 27.1 & 23.2 \\
\hline One-sided & 40.6 & 58.5 & 59.0 & 52.2 \\
\hline No exchange & 4.0 & 24.5 & 13.9 & 24.6 \\
\hline Total & 100.0 & 100.0 & 100.0 & 100.0 \\
\hline \multicolumn{5}{|l|}{ Emotional support } \\
\hline Reciprocal & 53.7 & 32.4 & 45.4 & 31.1 \\
\hline One-sided & 34.3 & 27.1 & 29.8 & 27.8 \\
\hline No exchange & 12.0 & 40.5 & 24.8 & 41.1 \\
\hline Total & 100.0 & 100.0 & 100.0 & 100.0 \\
\hline \multicolumn{5}{|c|}{ Norm of family support } \\
\hline Normative & 56.6 & 34.8 & - & - \\
\hline Circumstantial & 43.4 & 65.2 & - & - \\
\hline Total & 100.0 & 100.0 & - & - \\
\hline
\end{tabular}

measures of intergenerational relationships for middle-aged and elderly respondents are presented in Tables 4 and 5, respectively. For simplicity of analysis, both economic support and instrumental support were grouped together. The patterns of exchange were categorized as reciprocal, one-sided, and no exchange. A reciprocal exchange is a situation in which the adult children and their elderly parents mutually support one another. A one-sided exchange is a situation in which either adult child or the elderly parents provide disproportional support. Because cases of elderly parent benefactors in one-sided support were too small to be specified as a single category, no distinction is made as to the direction of transfer. A noexchange relationship is a situation in which neither the adult child nor the elderly parent provides support.

Table 5 Association among the dimensions of generational relationship for elders, 1998.

\begin{tabular}{|c|c|c|c|c|}
\hline \multirow[t]{2}{*}{ Dimension } & \multicolumn{2}{|c|}{ Geographic proximity } & \multicolumn{2}{|c|}{ Norm of family support } \\
\hline & Living together & Living separately & Normative & Circumstantial \\
\hline \multicolumn{5}{|c|}{ Instrumental/economic support } \\
\hline Reciprocal & 13.8 & 13.7 & 12.1 & 15.5 \\
\hline One-sided & 76.2 & 46.1 & 68.9 & 55.9 \\
\hline No exchange & 10.1 & 40.2 & 19.0 & 28.6 \\
\hline Total & 100.0 & 100.0 & 100.0 & 100.0 \\
\hline \multicolumn{5}{|c|}{ Emotional support } \\
\hline Reciprocal & 20.4 & 18.5 & 21.9 & 20.2 \\
\hline One-sided & 37.6 & 31.4 & 38.7 & 35.4 \\
\hline No exchange & 42.0 & 50.1 & 39.4 & 44.5 \\
\hline Total & 100.0 & 100.0 & 100.0 & 100.0 \\
\hline \multicolumn{5}{|c|}{ Norm of family support } \\
\hline Normative & 39.4 & 32.4 & - & - \\
\hline Circumstantial & 60.6 & 67.6 & - & - \\
\hline Total & 100.0 & 100.0 & - & - \\
\hline
\end{tabular}


Common patterns exist among the measures for both middle-aged and elderly adults. First, geographic proximity significantly prescribed the extent of observed support. The propensity for maintaining support through either reciprocal or one-sided mechanisms was stronger for coresident dyads than for non-coresident intergenerational pairs. Family support norms also differed by geographic proximity. Normative attitudes toward family support were seen more frequently among coresident generations. Family support norms were also closely related to the observed pattern of support. The propensity for maintaining economic and emotional support was greatest among middle-aged adults and elders who emphasized normative family support.

Overall, we observed significant associations among the three key areas of intergenerational relations: geographic proximity, exchange of support, and norms of family support. We found that coresidence helped promote exchanges of economic, instrumental, and emotional support between adult children and their elderly parents whereas independent households reported lower levels of exchange. Respondents with a normative or traditional attitude toward family support are more likely to engage in both intergenerational proximity and significant exchanges of support.

It is also noteworthy that marked contrasts exist in the pathways by which intergenerational exchanges are fulfilled by adult children as opposed to elderly parents. Reciprocity between coresident dyads was reported to be more prevalent by middle-aged adults than by elderly respondents. The percentage of middle-aged adults reporting reciprocal relationships in economic/instrumental support was $55.4 \%$. However, only $13.8 \%$ of elderly respondents reported a reciprocal relationship with their adult children. The pattern of emotional support shows a similar contrast between the two groups of respondents. Among those who coreside, the percentage reporting having reciprocal relationships in terms of emotional support was $53.7 \%$ of middle-aged adults and $20.4 \%$ of elderly respondents. Emotional isolation was more commonly reported by the elderly parents than by middle-aged adults. Approximately $42 \%$ of the elders reported having no emotional ties with their adult children even when coresiding with them, whereas only $12 \%$ of middle-aged adults made this claim.

Latent Structures of Intergenerational Relationships

The following section discusses the results from the analysis of the latent structure underlying joint distribution between geographic proximity, exchange of support, and norms of family support. Table 6 summarizes the results of the model that measured the latent structures for intergenerational relationships between middle-aged adults and elderly parents, respectively. We employed a complete independence model that assumed independence among the three dimensions of the intergenerational relationship. The model differentiated the number of latent patterns as two, three, four, and five patterns within which the three dimensions were independent from one another.

For the middle-aged sample, the model that assumed five latent patterns represents the best fit for the observed joint distribution among the three dimensions. For the elderly sample, the model that assumed three latent patterns represents the best fit for the observed distribution.

The following paragraphs present the probabilities of the latent pattern models and the conditional probabilities at each level for the observed dimensions for geographic proximity, exchange of support, and norms of family support estimated from the best-fit models described above.

When examining the latent patterns of intergenerational relationships for middle-aged adults (see Table 7), we found that Patterns I and II showed a greater tendency for coresidence compared with other observed patterns. The majority of middle-aged respondents represented 
Table 6 Model fitting of generational relationships for the middle-aged and elderly samples.

\begin{tabular}{|c|c|c|c|c|c|c|}
\hline \multirow[t]{2}{*}{ Variable } & \multicolumn{3}{|c|}{ Middle-aged } & \multicolumn{3}{|l|}{ Elderly } \\
\hline & $\mathrm{L}^{2}$ & $d f$ & $p$ & $\mathrm{~L}^{2}$ & $d f$ & $p$ \\
\hline Complete independence & 420.78 & 35 & $p<0.05$ & 511.48 & 35 & $p<0.05$ \\
\hline \multicolumn{7}{|l|}{ Number of latent classes } \\
\hline 2 & 90.46 & 22 & $p<0.05$ & 38.15 & 22 & $p<0.05$ \\
\hline 3 & 43.02 & 17 & $p<0.05$ & 19.52 & 17 & $p>0.05$ \\
\hline 4 & 43.02 & 17 & $p<0.05^{*}$ & 19.57 & 17 & $p>0.05^{*}$ \\
\hline 5 & 12.87 & 8 & $p>0.05$ & 2.36 & 2 & $p>0.05^{*}$ \\
\hline
\end{tabular}

*Identification problem occurred. Column rank was not equal to the number of estimators.

by Patterns III, IV, and V had a greater likelihood of living separately from their elderly parents. The instrumental and economic support variables for middle-aged adults in Pattern I showed significant contrast to other patterns, with the proportion of reciprocal relationships with elderly parents amounting to $99 \%$ among middle-aged adults in Pattern I. In contrast, middle-aged adults in Pattern II were more likely to maintain one-sided support relations. Those in Pattern III were more likely to maintain reciprocal relationships than those in Pattern IV. When reciprocal and one-sided exchanges were combined, however, middle-aged adults in Patterns III and IV were also likely to maintain strong support relationships. In contrast, those in Pattern V were less likely to maintain intergenerational support relationships, as $49 \%$ of respondents in this pattern did not have any type of support relation.

When interpreting the results for emotional support, we found that the majority ( $81 \%$ ) of middle-aged adults in Pattern I were most likely to engage in reciprocal relationships. Of those in Pattern II, 63\% maintained one-sided relationships with their elderly parents. The

Table 7 Coefficients (conditional probability) for five patterns of intergenerational relationships among middle-aged adults.

\begin{tabular}{|c|c|c|c|c|c|}
\hline \multirow[t]{3}{*}{ Dimension } & \multicolumn{5}{|l|}{ Latent class } \\
\hline & \multicolumn{2}{|l|}{ Strong } & \multicolumn{2}{|l|}{ Moderate } & \multirow{2}{*}{$\frac{\text { Weak }}{\mathrm{V}}$} \\
\hline & Reciprocal I & Traditional II & Circumstantial III & Normative IV & \\
\hline \multicolumn{6}{|c|}{ Geographic proximity } \\
\hline Living together & 0.57 & 0.44 & - & - & 0.04 \\
\hline Living separately & 0.43 & 0.56 & 1.00 & 1.00 & 0.96 \\
\hline \multicolumn{6}{|c|}{ Instrumental/economic support } \\
\hline Reciprocal & 0.99 & 0.12 & 0.36 & - & - \\
\hline One-sided & - & 0.86 & 0.55 & 0.83 & 0.51 \\
\hline No exchange & - & 0.03 & 0.09 & 0.17 & 0.49 \\
\hline \multicolumn{6}{|l|}{ Emotional support } \\
\hline Reciprocal & 0.81 & 0.32 & 0.45 & 0.56 & - \\
\hline One-sided & 0.11 & 0.63 & 0.42 & 0.12 & 0.21 \\
\hline No exchange & 0.08 & 0.05 & 0.13 & 0.32 & 0.79 \\
\hline \multicolumn{6}{|c|}{ Norm of family support } \\
\hline Normative & 0.51 & 0.65 & - & 0.58 & 0.21 \\
\hline Circumstantial & 0.49 & 0.35 & 1.00 & 0.42 & 0.79 \\
\hline Probability & 0.18 & 0.20 & 0.13 & 0.18 & 0.32 \\
\hline
\end{tabular}


majority (79\%) of middle-aged adults in Pattern V reflected emotional segregation from their elderly parents.

In terms of norms of family support, middle-aged adults in Patterns I, II, and IV were more likely to preserve normative attitudes toward family support whereas those in Patterns III and V perceived family support as circumstantial.

To summarize the results from the latent pattern analysis, many middle-aged children in Patterns I and II lived with their elderly parents and exchanged both instrumental/ economical and emotional support. The normative attitude toward family support also remained strong among these adults. The main contrast between adult children in Patterns I and II was in the level of engagement for reciprocity of support. Those in Pattern I were more likely to maintain reciprocal relationships than those in Pattern II. Adult children in Patterns III and IV were likely to represent an intermediate group in terms of the intensity of intergenerational relationships. Although the majority of adult children in Patterns III and IV lived separately from their elderly parents, they maintained intergenerational relationships, providing both material and emotional support. In particular, those in Pattern IV were likely to perceive family support as normative and maintained one-sided support.

Based on the distinct characteristics of each pattern, we isolated the type and extent of intergenerational relationships for adult children into five distinct patterns. Strong relationships based on reciprocity fell into Pattern I, strong relationships based on traditional family norm fell into Pattern II, circumstantial intermediate relationships fell into Pattern III, normative intermediate relationships fell into Pattern IV, and weak relationships fell into Pattern V. The distribution of these five patterns within the sample of middle-aged adults was $18,20,13,18$, and $32 \%$, respectively.

The best-fit model for intergenerational relationships among elderly respondents was one with three latent patterns. Table 8 summarizes the probabilities for the identified latent patterns and the conditional probabilities estimated under the best-fit model.

Each latent pattern showed significant differences for the characteristics between the three dimensions of intergenerational relationships. The majority (68\%) of elders in Pattern I lived

Table 8 Coefficients (conditional probability) for three patterns of intergenerational relationships among elderly adults.

\begin{tabular}{llll}
\hline Dimension & \multicolumn{2}{l}{ Latent class } & \\
\cline { 2 - 4 } & Traditional I & Reciprocal II & Weak III \\
\hline Geographic proximity & & & \\
$\quad$ Living together & 0.68 & 0.48 & 0.08 \\
Living separately & 0.33 & 0.52 & 0.92 \\
Instrumental/economic support & & & \\
Reciprocal & - & 0.71 & 0.01 \\
One-sided & 0.95 & 0.29 & 0.24 \\
No exchange & 0.05 & - & 0.75 \\
Emotional support & & & 0.14 \\
Reciprocal & 0.23 & 0.25 & 0.27 \\
One-sided & 0.42 & 0.37 & 0.59 \\
$\quad$ No exchange & 0.35 & 0.38 & 0.25 \\
Norm of family support & & & 0.75 \\
Normative & 0.44 & 0.30 & 0.31 \\
Circumstantial & 0.56 & 0.70 & \\
Probability & 0.50 & 0.20 & \\
\hline
\end{tabular}


with their children. The prevalence of coresidence in this group represented a clear contrast to elders in Pattern III, of whom only $8 \%$ lived with their children. The percentage of elderly parents who lived with adult children accounted for $48 \%$ of the respondents in Pattern II.

The three latent patterns also differed significantly in regard to the extent and mechanisms by which instrumental and economic support flowed between generations. Virtually all (95\%) of the elders in Pattern I maintained one-sided support relationships with their adult children. In contrast, the majority (71\%) of those in Pattern II maintained reciprocal relationships. The majority $(75 \%)$ of the elders in Pattern III appeared unlikely to maintain any support relationships.

Differences in emotional support among the latent patterns were less clear. The majority of the elders in Patterns I and II were likely to maintain any type of support relationship with their adult children. Among the elders in Pattern III, more than half (59\%) were likely to feel emotionally segregated. Normative attitudes toward family support among elderly parents were most prevalent among those in Pattern I. Of the elders in Pattern I, 44\% had a strong sense of family support, compared with $30 \%$ of those in Pattern II. As would be expected, the elders in Pattern III were most likely to perceive family support as circumstantial.

To summarize the primary characteristics of each latent pattern for elderly respondents, Pattern I represented the group closest to idealized traditional relationships. As such, the elders in this pattern were more likely than elders in other patterns to live with their children, receive substantial material help, and take family support for granted. Pattern II represented elderly parents engaging in relationships based on reciprocity. They maintained reciprocal relationships with their adult children regardless of living arrangements. Pattern III was characteristic of weak relationships with adult children. Most of the elders in Pattern III lived separately and were not integrated into their adult children's lives. The intergenerational segregation typical of those in Pattern III reinforces and reflects their indifferent attitude toward family support. The relative composition of traditional, reciprocal, and weak relationship groups among the elderly parent sample is 50,20 , and $31 \%$, respectively.

\section{Determinants of Latent Patterns of Intergenerational Relationship}

As discussed in the preceding section, intergenerational relationships between adult children and their elderly parents are composed of several distinct patterns. Which adult children and which elderly parents are more likely to have certain relationship patterns compared with others? What characteristics differentiate middle-aged adults with reciprocal, traditional, or no intergenerational relationships? How do elders with traditional, reciprocal, or no intergenerational relationships differ from one another? This section addresses these issues by examining covariates that significantly influence the latent patterns of intergenerational relationships.

To perform the multivariate analysis on the latent patterns of intergenerational relationships, we allocated pattern values to individual cases in a series of steps. First, we estimated the probability of each latent pattern for individual cases based on the estimated probabilities of the identified latent pattern and the conditional probabilities of the observed dimensions in the best-fit model. Next, in proportion with distribution of latent patterns, we allocated the pattern value to the individual cases using a random imputation method.

Tables 9 and 10 summarize the results from the multinomial logit analysis for middle-aged adults. We analyzed male and female respondents separately. The dependent variable in this model represents the five latent patterns describing intergenerational relationships with elderly parents. The reference pattern for the dependent variable was Pattern V (weak) relationship. The coefficients presented in the tables refer to the log value of the odds ratios for being found in the specific latent pattern (Patterns I-IV) as opposed to being found in the weak relationship (Pattern V) according to unit change in covariates. 
Table 9 Determinants of intergenerational relationships for middle-aged Men $(N=467)$.

\begin{tabular}{|c|c|c|c|c|}
\hline \multirow[t]{4}{*}{ Variable } & \multicolumn{4}{|l|}{ Latent class } \\
\hline & \multicolumn{2}{|l|}{ Strong } & \multicolumn{2}{|l|}{ Moderate } \\
\hline & Reciprocal I & Traditional II & Circumstantial III & Normative IV \\
\hline & $b$ & $b$ & $b$ & $b$ \\
\hline \multicolumn{5}{|l|}{ Husband's age } \\
\hline $45-49$ & -0.54 & 0.08 & 0.31 & 0.27 \\
\hline $50-54$ & 0.45 & $0.70^{\wedge}$ & 0.12 & 0.24 \\
\hline $55-59$ & $-2.00 *$ & 0.54 & 0.10 & -0.24 \\
\hline \multicolumn{5}{|l|}{ Husband's sibling order } \\
\hline Eldest & $1.55 * * *$ & 0.48 & $0.98 * * *$ & $0.61^{\wedge}$ \\
\hline Husband's number of siblings & $-0.30 * *$ & 0.03 & -0.11 & 0.09 \\
\hline \multicolumn{5}{|l|}{ Husband's education } \\
\hline Primary school & -2.04 & -0.14 & -34.73 & -1.61 \\
\hline Middle school & -0.97 & -0.41 & 0.94 & -0.34 \\
\hline High school & -0.49 & -0.69 & 0.56 & -0.29 \\
\hline \multicolumn{5}{|l|}{ Husband's occupation } \\
\hline Clerical & 0.07 & -0.02 & 0.17 & -0.51 \\
\hline Service/sales & 0.59 & 0.97 & -0.34 & 0.14 \\
\hline Production, not work & -0.80 & 0.72 & -0.96 & -0.74 \\
\hline Agricultural & $2.85^{*}$ & 1.21 & -34.50 & -34.50 \\
\hline \multicolumn{5}{|l|}{ Wife's education } \\
\hline Primary school & -0.16 & -0.93 & 0.39 & 0.28 \\
\hline Middle school & 0.20 & -0.88 & $-1.62 *$ & $-1.12^{\wedge}$ \\
\hline High school & 0.74 & -0.31 & -0.66 & -0.01 \\
\hline Income level & -0.14 & -0.07 & -0.22 & -0.05 \\
\hline \multicolumn{5}{|l|}{ Home ownership } \\
\hline Own & $1.02 *$ & 0.64 & 0.75 & 0.24 \\
\hline Perceived economic status & 0.19 & 0.20 & 0.04 & 0.11 \\
\hline \multicolumn{5}{|l|}{ Residence } \\
\hline City & -0.55 & $-0.72^{\wedge}$ & 0.05 & -0.56 \\
\hline Constant & -0.23 & -1.30 & -0.00 & -0.25 \\
\hline
\end{tabular}

The number of cases (467) employed in the logit analysis is smaller than that of original male respondents (474) due to some missing cases of covariates in the analysis. Reference groups are: pattern of latent class (Pattern V, weak); husband's age (40-44); husband's sibling order (others); husband's education (college); husband's occupation (professional); wife's education (college); home ownership (does not own); residence (rural). $* * * p<0.001 ; * * p<0.01 ; * p<0.05 ; \wedge p<0.1$.

Husband's sibling order was estimated to be statistically significant for both male and female respondents. As has been found in many others studies, the eldest child is more likely than other children to maintain intergenerational relationships with aged parents. Place of residence also significantly impacted adult children's relationships with their parents. Adult children in urban areas were significantly less likely $(p<0.10)$ than those in rural areas to maintain strong traditional relationships.

Age differences are also interesting. For male respondents, the likelihood of a strong reciprocal relationship (Pattern I) became stronger among younger adults. The relatively higher propensity toward reciprocal relationships among younger adults implies that their relationships change from reciprocal to non-reciprocal as they age. It also likely reflects a generational 
Table 10 Determinants of intergenerational relationships for middle-aged women $(N=341)$.

\begin{tabular}{|c|c|c|c|c|}
\hline \multirow[t]{4}{*}{ Variable } & \multicolumn{4}{|l|}{ Latent class } \\
\hline & \multicolumn{2}{|l|}{ Strong } & \multicolumn{2}{|l|}{ Moderate } \\
\hline & Reciprocal I & Traditional II & Circumstantial III & Normative IV \\
\hline & $b$ & $b$ & $b$ & $b$ \\
\hline \multicolumn{5}{|l|}{ Husband's age } \\
\hline $45-49$ & 0.10 & 0.24 & -0.08 & -0.53 \\
\hline $50-54$ & -0.43 & 0.29 & -0.48 & -0.28 \\
\hline $55-59$ & -0.23 & 0.81 & -0.05 & -0.49 \\
\hline \multicolumn{5}{|l|}{ Husband's sibling order } \\
\hline Eldest & $1.06 * * *$ & $0.66^{\wedge}$ & $0.97 *$ & 0.62 \\
\hline Husband's number of siblings & -0.03 & -0.11 & 0.15 & -0.06 \\
\hline \multicolumn{5}{|l|}{ Husband's education } \\
\hline Primary school & -0.97 & -0.47 & -37.25 & -38.22 \\
\hline Middle school & 1.00 & 0.73 & $2.46^{*}$ & $1.88^{*}$ \\
\hline High school & -0.19 & -0.27 & $1.72 * *$ & 0.17 \\
\hline \multicolumn{5}{|l|}{ Husband's occupation } \\
\hline Clerical & -0.89 & -0.84 & $-1.46^{*}$ & $-1.12^{\wedge}$ \\
\hline Service/sales & -0.94 & -0.49 & $-2.18 * *$ & $-1.68^{*}$ \\
\hline Production, not work & -1.05 & -0.61 & $-1.91^{*}$ & -1.02 \\
\hline Agricultural & -0.03 & -0.67 & -1.96 & -39.54 \\
\hline \multicolumn{5}{|l|}{ Wife's education } \\
\hline Primary school & -1.03 & -1.54 & $-2.74 *$ & -1.62 \\
\hline Middle school & $-1.63^{\wedge}$ & $-1.92 *$ & $-3.40 * * *$ & $-2.11^{*}$ \\
\hline High school & $-1.89 * *$ & $-1.07^{\wedge}$ & $-2.68 * * *$ & $-1.27^{\wedge}$ \\
\hline \multicolumn{5}{|l|}{ Wife's economic activity } \\
\hline Work & 0.27 & $0.74 *$ & 0.33 & 0.31 \\
\hline Income level & 0.11 & -0.01 & -0.18 & -0.04 \\
\hline \multicolumn{5}{|l|}{ Home ownership } \\
\hline Own & -0.01 & -0.12 & 0.28 & $1.04^{\wedge}$ \\
\hline Perceived economic status & 0.11 & 0.06 & -0.12 & $0.46^{*}$ \\
\hline \multicolumn{5}{|l|}{ Residence } \\
\hline City & -0.76 & $-0.83^{*}$ & -0.05 & -0.06 \\
\hline Constant & 1.55 & 1.77 & 1.63 & -0.23 \\
\hline
\end{tabular}

The number of cases (341) employed in the logit analysis is smaller than that of original female respondents (390) due to some missing cases of covariates in the analysis. Reference groups are: pattern of latent class (Pattern V, weak); husband's age (40-44); husband's sibling order (others); husband's education (college); husband's occupation (professional); wife's education (college); wife's economic activity (does not work); home ownership (does not own); residence (rural). ${ }^{* * *} p<0.001 ;{ }^{*} p<0.01 ;{ }^{*} p<0.05 ;{ }^{\wedge} p<0.1$.

replacement. The age effect of adult children could also simply represent that of their elderly parents. It is beyond the current analysis to determine which factor is more relevant.

Having a greater number of siblings significantly reduced the likelihood of maintaining a reciprocal relationship with elderly parents. This finding might be a reflection of role transfer or competition among many siblings, both of which could reduce the likelihood of dyadic relationships between parent and child.

Agricultural workers were more likely than individuals with other occupations to maintain strong reciprocal relationships with their elderly parents. This distinctive pattern of intergenerational relationships among agricultural workers seems to be related to the 
observed effect for place of residence. Adult children in rural areas were more likely than urban residents to maintain strong intergenerational relationships in both reciprocal and traditional support patterns. When adult children live in rural areas and engage in farming or fishing, it is more likely that their elderly parents will reside with them or be co-local, helping with farm work or housekeeping or receiving help from children living with them or nearby.

For female respondents, the odds of intermediate exchange decreased when husband's education was college-level or higher compared with being at the middle- or high-school level. Interestingly, however, the likelihood of maintaining intergenerational relationships of any form was greatest when female respondents had college-level or higher education. These results are somewhat counterintuitive, as it has been argued that children with higher education levels are more likely to prefer privacy and independence and less likely to

Table 11 Determinants of intergenerational relationships for elderly adults $(N=2,301)$.

\begin{tabular}{|c|c|c|}
\hline \multirow[t]{3}{*}{ Variable } & \multicolumn{2}{|l|}{ Latent class } \\
\hline & \multirow{2}{*}{$\frac{\text { Traditional I }}{b}$} & \multirow{2}{*}{$\frac{\text { Reciprocal II }}{b}$} \\
\hline & & \\
\hline \multicolumn{3}{|l|}{ Gender } \\
\hline Male & 0.01 & -0.07 \\
\hline \multicolumn{3}{|l|}{ Age } \\
\hline $70-74$ & 0.01 & -0.09 \\
\hline $75-79$ & $0.34 *$ & $0.13 *$ \\
\hline $80+$ & $0.52 *$ & 0.28 \\
\hline \multicolumn{3}{|l|}{ Marital status } \\
\hline Married & $-0.65^{* * *}$ & -0.14 \\
\hline \multicolumn{3}{|l|}{ Health status } \\
\hline Problems with 1-2 ADLs & 0.11 & $0.38^{*}$ \\
\hline Problems with 3 ADLs & 0.42 & 0.53 \\
\hline Problems with more than 3 ADLs & -0.72 & 0.21 \\
\hline Number of children & $0.12 * * *$ & $0.21 * * *$ \\
\hline \multicolumn{3}{|l|}{ Residence } \\
\hline City & -0.04 & -0.10 \\
\hline \multicolumn{3}{|l|}{ Educational level } \\
\hline Primary school & $0.58 * * *$ & $0.57 * *$ \\
\hline Individual income & $-0.58 * * *$ & $-0.46^{* * *}$ \\
\hline \multicolumn{3}{|l|}{ Economic activity } \\
\hline Work & -0.20 & $1.21 * * *$ \\
\hline Social activity & 0.10 & $0.25 * *$ \\
\hline Family income & $0.49 * * *$ & $0.42 * * *$ \\
\hline \multicolumn{3}{|l|}{ Home ownership } \\
\hline Own & 0.03 & $0.40 *$ \\
\hline Constant & $-0.87^{*}$ & $-3.51^{*}$ \\
\hline
\end{tabular}

The number of cases $(2,301)$ employed in the logit analysis is smaller than that of original elder respondents $(2,496)$ due to some missing covariates in the analysis. ADL = activity of daily living. Reference groups are: pattern of latent class (Pattern III, weak); gender (female); age (65-69); marital status (not married); health status (no problems); residence (rural); educational level (middle school or more); individual income $(1=$ low, $4=$ high); economic activity (does not work); social activity $(0=$ weak, $5=$ strong); family income $(1=$ low, $10=$ high); home ownership (does not own). ${ }^{* *} p<0.001 ;{ }^{*} p<0.01 ;{ }^{*} p<0.05$. 
exercise interaction and filial piety. Although we do not present our results here, we also found that probability of coresidence was significantly lower among those with higher educational levels. This, combined with the finding that the exchange of instrumental and economic support was more frequently made by those with higher educational levels, suggests that the positive effect of wife's education on intergenerational relationships is likely to be related to its effect on economic ability rather than attitudinal formation.

Table 11 summarizes the results of a multinomial logit analysis for the intergenerational relationships for elderly respondents in relation to their adult children. Here the reference category for the dependent variable was Pattern III (weak) relationship. Most covariates measured in this model reflect statistically significant effects on the odds of being a member of a specific pattern of intergenerational relationship. Among these covariates, the effects of age, marital status, and educational level all suggest that lack of independence in attitude or resources enhanced intergenerational relationships regardless of type. The likelihood of maintaining intergenerational relationships with either a traditional or reciprocal focus increased with age. Elderly parents without partners were more likely than their married counterparts to maintain traditional intergenerational relationships. Similarly, elderly parents with low educational levels were more likely than other elders to maintain traditional intergenerational relationships with their adult children.

Importantly, the model also shows that the level of self-reliance among the elders contributes to promoting intergenerational relationships - not to weakening them. The likelihood of reciprocal relationships was greater when the elders were employed and engaged in many social activities.

The number of children had a significant impact on determining membership in a specific intergenerational relationship pattern. The likelihood of maintaining an intergenerational relationship in either a traditional or reciprocal way increased with the number of children. This suggests that both the chance of living with at least one child and obtaining a sufficient net amount of family support increased with the number of available children. Family income also significantly enhanced the likelihood of traditional or reciprocal transfers between generations.

In summary, membership in a specific pattern of intergenerational relationship for elderly parents appears to be driven by circumstances of need and by the opportunity to obtain support. As would be expected, the need for traditional or reciprocal intergenerational relationships was greatest among the elderly adults with the weakest economic status. However, the availability of family support was essential in addressing this need of intergenerational support. That is, even if the elderly parent were to recognize a need for support, if the adult child or children lacked the economic, geographic, or social resources to meet this need, we would expect the net result to be higher poverty rates among these elderly parents.

\section{Discussion}

The present study examined the structural characteristics of intergenerational relationships and the underlying observed associations between geographic proximity, exchange of support, and family support norms. We used maximum likelihood latent structure analysis to discover the latent patterns underlying the associations within these dimensions of intergenerational relationships. Taking into account clear attitudinal differences in intergenerational relationships between generations, we performed separate analyses from the perspectives of middle-aged and elderly adults. 
The results showed that perspectives on intergenerational relationships differ significantly between middle-aged and elderly adults. Intergenerational relationships among middle-aged adults comprise five distinct patterns: strong reciprocal (18\%), strong traditional $(20 \%)$, intermediate circumstantial $(13 \%)$, intermediate normative $(18 \%)$, and weak (32\%). By interpreting covariates for each relationship pattern, we see that the strong traditional relationship is strongest for those who live in rural areas, work at farm or fishery occupations, are the eldest child, are highly educated, and are older. The strong reciprocal relationship is most frequently observed among those who live in rural areas, work at farm or fishery occupations, are the eldest child, are highly educated, and are younger in age. Moderate relationships are characteristic of eldest children and those who are highly educated. These results suggest that intergenerational relationships remain solid for two very distinct demographic groups. One group consists of adults who represent traditional traits and beliefs, whereas the other group consists of the new generation of adults with high levels of education and significant economic resources. Based upon what researchers have seen in the West, this pattern may reflect a transition from the direct provision of care to the purchasing of care by adult children for their elderly parents. However, the current data does not allow us to offer this as more than a suggestion of what might be occurring in Korean society.

The interpretation of intergenerational relationships from the perspective of elderly parents is more straightforward, with only three relationship patterns emerging from the latent model: traditional (50\%), reciprocal (20\%), and weak (31\%). Elderly parents in traditional relationships often live with at least one of their children and receive regular support from their children. The elders in this pattern are generally older, have no partner, and are poorly educated. All of these characteristics are suggestive of the elders' lack of self-reliance and their need for support. Importantly, the analysis shows that family resources are important for maintaining traditional support relationships regardless of the level of need. The elders who are members of a reciprocal relationship are likely to work and engage in many social activities, implying that self-reliance and social participation promote greater intergenerational integration. The elders in weak relationships are either those capable of managing their life or those unable to receive family support even in need of help.

In conclusion, this study highlights intergenerational and socioeconomic differences in intergenerational proximity, material and emotional support, and attitudes toward familial support. Current intergenerational relationship formation in Korea is likely to reflect a specific Korean path of family change. The substance of family change is not the erosion of family ties but the diversification of family relationships. Increasing heterogeneity of family relationships also reflects the growing importance of socioeconomic factors in determining family ties. As this article clearly shows, it is less a question of whether or not intergenerational relationships will survive in Korea and more a question of the way in which intergenerational behaviors will continue to be reconstructed in response to the changes reshaping them.

\section{References}

Burr, J., \& Mutchler, J. (1991). Longitudinal analysis of household and nonhousehold living arrangements in later life. Demography, 28, 375-390.

Chang, K.-S. (1997). The neo-Confucian right and family politics in South Korea: The nuclear family as an ideological construct. Economy and Society, 26, 22-42.

Choi, J.-S. (2002). Hanguk eui chogi sawheihak kwa kajok yungu, [Early studies on sociology and family in Korea]. Seoul: Iillji sa.

DaVanzo, J., \& Goldscheider, F. K. (1989). Pathways to independent living in early adulthood: Marriage, semi-autonomy, and premarital residential independence. Demography, 26, 597-614. 
Dowd, J. (1975). Aging as exchange: A preface to theory. Journal of Gerontology, 30, 584-594.

Eliason, S. (1997). The categorical data analysis system: Supplemental user's manual for command line, prerelease version 4.0 of Prog MLLSA for DOS and OS/2. Iowa: The University of Iowa.

Hogan, D., Eggebeen, D., \& Clogg, C. (1993). The structure of intergenerational exchanges in American families. American Journal of Sociology, 98, 1428-1458.

Jung, K.-H., Joe, A.-J., Oh, Y.-H., Byun, J.-G., \& Moon, H.-S. (1998). Noin saingwhal siltai josa mit bokji yokgu josa [Survey on living condition and welfare need of the elderly]. Seoul: Korean Institute of Health and Social Affairs.

Kim, D.-S., Park, K.-S., \& Lee, S.-Y. (1999). Hanguk chungyun cheung eui sedai kwankye wa nohu buyang kwan, [Intergenerational relationship and attitude toward old age security among Korean middle adults]. Hanguk Inguhak, Korean Journal of Population Association, 23/1, 55 - 90.

Korean National Statistical Office (1966). Census of population and housing. Seoul: Korean National Statistical Office.

Korean National Statistical Office (1980). Census of population and housing. Seoul: Korean National Statistical Office.

Korean National Statistical Office (1985). Census of population and housing. Seoul: Korean National Statistical Office.

Korean National Statistical Office (1990). Census of population and housing. Seoul: Korean National Statistical Office.

Korean National Statistical Office (1995). Census of population and housing. Seoul: Korean National Statistical Office.

Korean National Statistical Office (1999). Social indicators in Korea. Seoul: Korean National Statistical Office.

Korean National Statistical Office (2000). Census of population and housing. Seoul: Korean National Statistical Office.

Kwon, T.-H., \& Park, Y.-J. (1995). Kajok eui kujo wa yuhyung, Structures and Patterns of families. In T.-H. Kwon, T.-H. Kim, \& J.-H. Choi (Eds.), Hanguk eui ingu wa kajok, [Population and family of Korea] (pp. 269-365). Seoul: Illshin-Sa.

Litwak, E. (1985). Helping the elderly: The complementary roles of informal networks and formal systems. New York: Guilford.

Park, K-S. (1999). Noin eui saingwhal kwa salm eui jil, The living environment and life quality of the elderly. In I-K. Kim, D-B. Kim, S-H. Mo, K-S. Park, Y-H. Won, Y-S. Lee, S-N. Cho (Eds.), Hanguk noin eui salm; Jindan kwa chonmang, [Life of elderly Koreans: Issues and prospects] (pp. 365-404). Seoul: Mirae-Inryuk-Kaibal.

Phua, V. C., Kaufman, G., \& Park, K. S. (2001). Strategic adjustments of elderly Asian Americans: Living arrangements and headship. Journal of Comparative Family Studies, 32, 263-281.

Shanas, E. (1980). Older people and their families: The new pioneers. Journal of Marriage and the Family, $42,9-15$.

Silverstein, M., \& Bengtson, V. (1997). Intergenerational solidarity and the structure of adult child-parent relationships in American families. American Journal of Sociology, 103, 429-460.

Wolf, D., \& Soldo, B. (1988). Household composition choices of older unmarried women. Demography, 25, 387-403. 